\title{
The biology of Strongyloides spp.
}

\author{
Mark E. Viney ${ }^{1 \S}$ and James B. Lok ${ }^{2}$ \\ ${ }^{1}$ School of Biological Sciences, University of Bristol, Bristol, BS8 1TQ, UK \\ ${ }^{2}$ Department of Pathobiology, School of Veterinary Medicine, University of Pennsylvania, \\ Philadelphia, PA 19104-6008, USA
}

\section{Table of Contents}

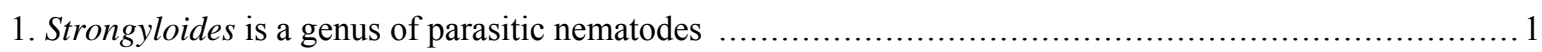

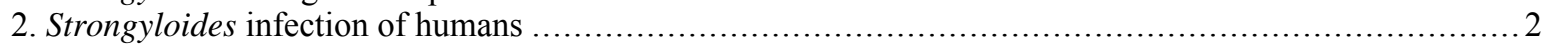

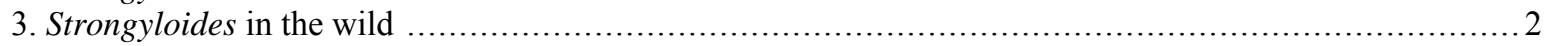

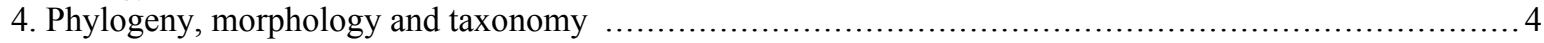

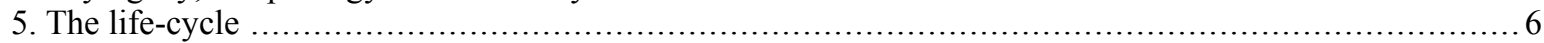

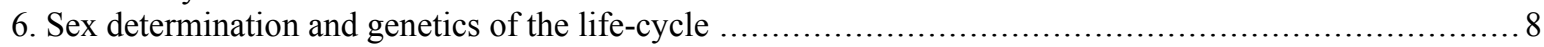

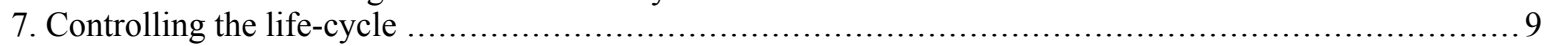

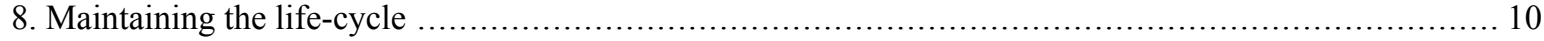

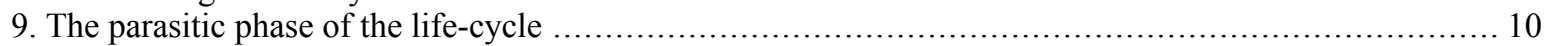

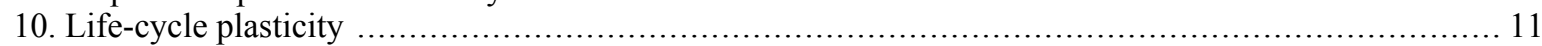

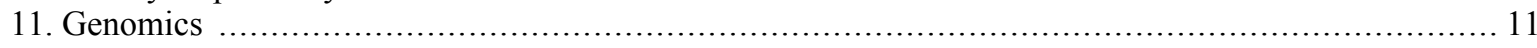

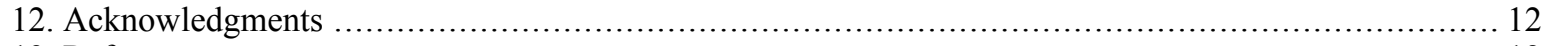

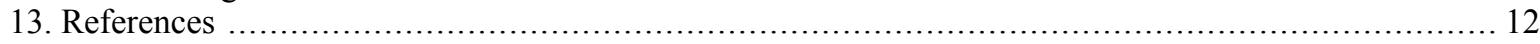

\section{Abstract}

Strongyloides is a genus of parasitic nematodes that, unusually, has a free-living adult generation. Here we introduce the biology of this genus, especially the fascinating but complex life-cycle, together with an overview of the taxonomy, morphology, genetics, and genomics of this genus.

\section{Strongyloides is a genus of parasitic nematodes}

Strongyloides is a genus containing some 50 species of obligate gastrointestinal parasites of vertebrates (Speare, 1989). Strongyloides infects mammals, birds, reptiles and amphibians. Where investigated, most species appear to be able to infect one, or at most a very few, host species. Indeed, in many cases the specific designation

\footnotetext{
*Edited by Marie-Anne Félix, Robin B. Gasser, and David Bird Last revised September 20, 2013. Published July 16, 2015. This chapter should be cited as: Viney M.E., Lok J.B. The biology of Strongyloides spp. (July 16, 2015), WormBook, ed. The C. elegans Research Community, WormBook, doi/10.1895/wormbook.1.141.2, http://www.wormbook.org.

Copyright: (C) 2015 Mark E. Viney and James B. Lok. This is an open-access article distributed under the terms of the Creative Commons Attribution License, which permits unrestricted use, distribution, and reproduction in any medium, provided the original author and source are credited.

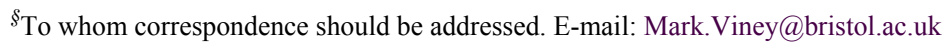


may have been attributed largely by the host species in which the parasite was found. This degree of host-species specificity is not unusual among animal parasitic nematodes.

For most nematodes that parasitise the vertebrate gastrointestinal tract, male and female worms live in the host gut and the females lay eggs that pass out of the host in faeces. Depending on the species, these eggs, or infective larvae that develop from them, are eaten (eggs or larvae) or penetrate host skin (larvae) to achieve transmission to a new host. There is then often a period of larval migration within the new host before new adults establish in the gut. Strongyloides follows this basic plan, but with significant differences. Female-only adult worms form the parasitic stages of Strongyloides. In addition, there is a dioecious adult generation that occurs outside of the host (Schad, 1989). This free-living adult generation is almost unique among nematode parasites of vertebrates. Originally the parasitic and free-living adult generations of Strongyloides were described as distinct species of Anguillula (Bavay, 1876; Bavay, 1877) until they were discovered to be separate stages of one life-cycle when they were brought together as Strongyloides (Grassi, 1879).

\section{Strongyloides infection of humans}

Two species of Strongyloides infect humans, S. stercoralis and S. fuelleborni. S. stercoralis has a cosmopolitan distribution in tropical and subtropical regions (Schad, 1989). S. fuelleborni occurs in African primates where infection can be shared with humans (Pampiglione and Ricciardi, 1972; Hira and Patel, 1980). S. fuelleborni kellyi occurs exclusively in humans in New Guinea (Ashford and Barnish 1989; Ashford et al., 1992). It is estimated that some 100-200 million individuals are infected worldwide with Strongyloides, however these infections can be difficult to detect, so these may be underestimates (Crompton, 1987; Albonico et al., 1999; Requena-Mendez et al., 2013). For comparison, global human infection with the gastro-intestinal nematodes Ascaris lumbricoides, Trichuris trichiura, and hookworms (Ancylostoma duodenale and Necator americanus) are 1.4, 1.0, and 1.4 billion, respectively (Albonico et al., 1999).

In normal, healthy individuals infection with Strongyloides causes rather little overt pathology (Genta and Caymmi Gomes, 1989; Grove, 1989a), but may compromise an individual's nutritional status (Stephenson et al., 2000). However, Strongyloides infection in immunocompromised individuals (particularly following the administration of steroids, for example following transplant surgery) can result in disseminated strongyloidiasis, in which worms, particularly larvae, move beyond the confines of the gut into other organs (Grove 1989a; Buonfrate et al., 2013) (see Section 5). This is fatal unless anti-Strongyloides therapy is given. S. fuelleborni kellyi is also the aetiological agent of swollen baby (or belly) syndrome in New Guinea, in which neo-natal infants acquire overwhelming intestinal infections that can also disseminate (Ashford and Barnish, 1989). This is also fatal in the absence of anti-Strongyloides therapy.

\section{Strongyloides in the wild}

Strongyloides is a relatively common infection of wild and domestic animals. Although it is difficult to generalise, the prevalence (i.e., the proportion of a population that is infected) of S. stercoralis infections of humans is often up to $5 \%$ in endemic areas with this typically concentrated in younger individuals (which is common for many soil transmitted helminths), with the occasional occurrence of higher prevalence. In a study of rats in the UK the prevalence of $S$. ratti was $62 \%$ (Fisher and Viney, 1998). The relative difficulty of detection of Strongyloides infections affects the accuracy of reported estimates of prevalence (Requena-Mendez et al., 2013).

Strongyloides infections can be detected by examination of host faeces for Strongyloides eggs or larvae, or by examination of the small intestine of a host for parasitic females.

Faeces. In freshly isolated faeces direct examination of a thick smear will reveal eggs and/or L1 stages. The eggs are ellipsoid, $40-85 \mu \mathrm{m}$ in length, with a thin wall containing a larva (Figure 1). This morphology identifies the eggs as Strongyloides; the presence of larvae in fresh faeces is also diagnostic of Strongyloides infection. The stage (eggs or larvae) present in faeces is a species-specific character (Figure 1). In this way, for example, S. stercoralis and $S$. fuelleborni infections can be differentiated by the presence of larvae or eggs, respectively. 


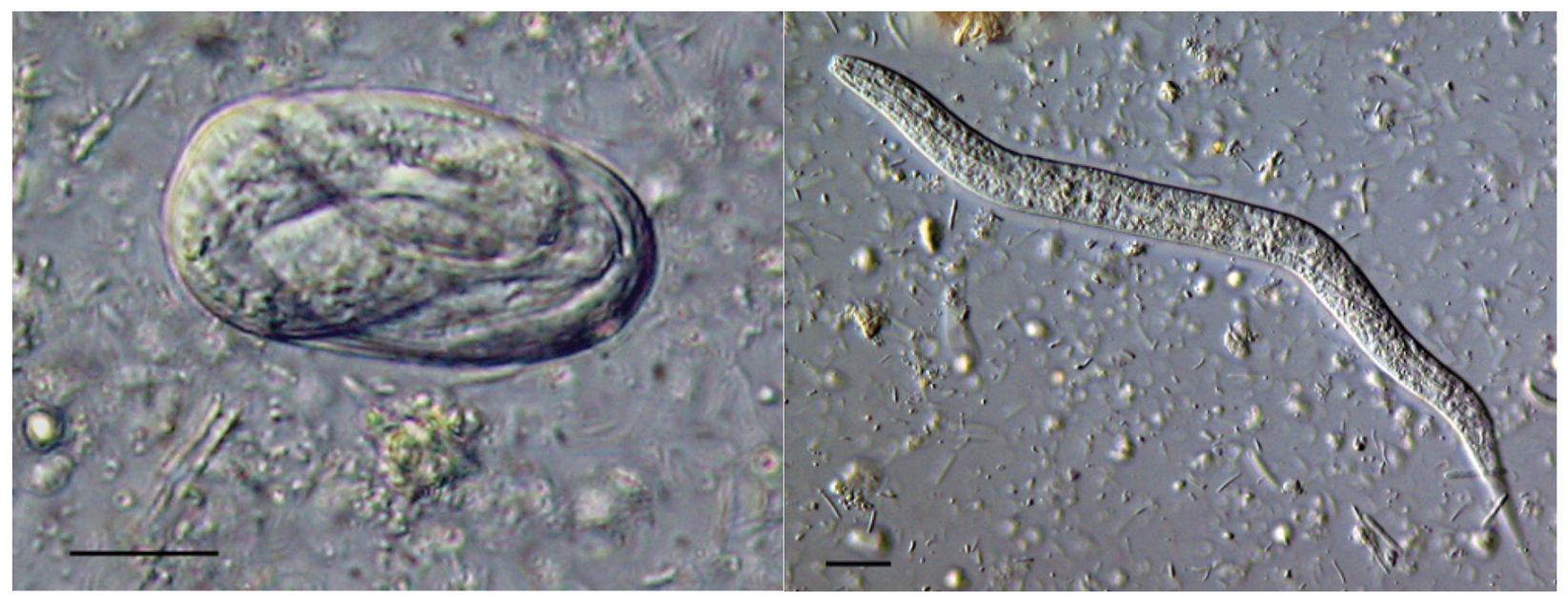

Figure 1. An egg and a first stage larva (left and right, respectively) of $\boldsymbol{S}$. ratti in fresh faeces. Scale bars $=10 \mu \mathrm{m}$

Faeces can be sampled by collection of fresh faeces from the ground, by collection directly from the rectum (of large domestic animals) or, for humans, from volunteered stool samples. Direct examination of faeces can diagnose relatively high intensity (i.e., a large number of worms per host) Strongyloides infections. For lower intensity infections larvae can be collected from a greater faecal mass by the use of a Baermann funnel (see Strongyloides stercoralis: a model for translational research on parasitic nematode biology) or by nematode egg concentration techniques on formalin preserved stool samples (Requena-Mendez et al., 2013). Faecal samples can also be grown in faecal cultures from which infective L3s can be obtained (see Section 8, and Strongyloides stercoralis: a model for translational research on parasitic nematode biology). The infective L3 morphology (see Section 4) will identify Strongyloides larvae.

It is important to examine fresh faeces for two reasons (Ashford and Barnish, 1989). First, Strongyloides eggs rapidly hatch to release larvae and so examination of fresh faeces allows proper determination of the stage passed in faeces. Second, faeces collected from the ground can be rapidly contaminated by free-living nematodes, making the subsequent identification and collection of Strongyloides larvae more difficult.

Strongyloides parasitic females can be observed in the small intestine of infected hosts. This, obviously, requires the sacrifice of the host. Strongyloides parasitic females are, in general, concentrated in the upper half-to-third of the small intestine. Direct microscopical examination can reveal parasitic females or, more usually, the trails of dark eggs left behind the female as she migrates through the intestinal mucosa (Figure 2). To do this the intestine is opened longitudinally and the luminal contents removed; easier viewing can be achieved by squashing the open small intestine between two glass plates, which are then examined microscopically (Wilkes et al., 2004). Live parasitic females can be obtained by vertically suspending longitudinally opened intestines in media (Wilkes et al., 2004). 


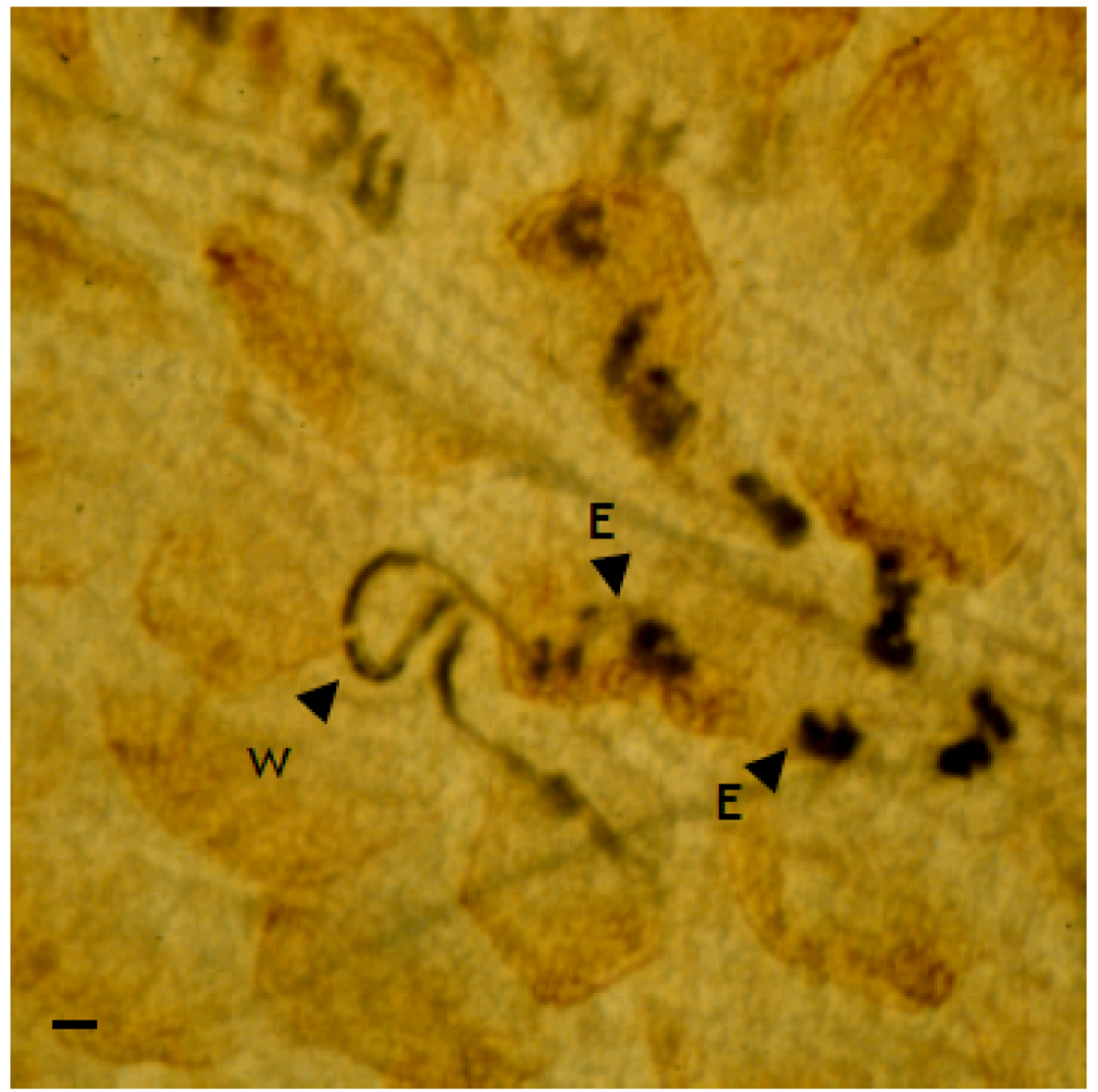

Figure 2. A S. ratti parasitic female (W) and her trail of eggs (E) in situ in the small intestine of a rat. Scale bar $=100 \mu \mathrm{m}$

\section{Phylogeny, morphology and taxonomy}

Nematode phylogenetic reconstruction based on rRNA SSU places Strongyloides (Rhabditida, Strongyloididae) (Anderson, 2000) in clade IVa, which is a sister clade to plant parasitic and invertebrate parasitic nematodes (clade IVb) (Blaxter et al., 1998). C. elegans (Rhabditida, Rhabditidae) is in clade V together with other parasitic nematodes (order Strongylida). Therefore the taxonomic arrangement of Caenorhabditis and Strongyloides is not consistent with the reconstructed phylogeny. Note the difference between the taxonomic order Strongylida and its superfamily Strongyloidea, which contains Clade V parasites such as the true strongyles of equids, and the family Strongyloididae (order Rhabditida, Clade IVa), which contains Strongyloides spp. Similarities in naming of these divergent taxa are potential sources of great confusion. Furthermore, note that this chapter is about the genus Strongyloides, but that there is a quite different genus of nematodes, Strongylus.

Parastrongyloides is the sister genus to Strongyloides (Dorris et al., 2002). Parastrongyloides has a similar life-cycle to Strongyloides except that there are parasitic males as well as females, and the free-living forms are able to go through multiple, sequential generations outside of the host, apparently indefinitely (see Section 5) (Grant et al., 2006a). Parastrongyloides was first described from moles but is more widely known from Australasian marsupials (Morgan, 1928; Mackerras, 1959).

Molecular phylogenetic analysis of Strongyloides has suggested the existence of two clades within the genus (Dorris et al., 2002). This analysis has not been able to separate morphologically defined species, including $S$. stercoralis and S. fuelleborni. 
The morphology of the parasitic and free-living phases of the life-cycle differs. The parasitic females for many species are approximately $2 \mathrm{~mm}$ in length (some species are larger, up to $5 \mathrm{~mm}$ ), with blunt-ended tails, and an elongated, straight-sided (filariform) oesophagus, occupying approximately one third of the body length (Figure 3) (Speare, 1989). The ovary is didelphic and opens at the vulva, which is positioned approximately two thirds along the body length. The free-living adult stages are approximately $1 \mathrm{~mm}$ in length, with the female slightly larger than the male (Figure 4). Both sexes have a rhabditiform oesophagus; the free-living female has a didelphic ovary and a vulva at the mid-point of the body (Speare, 1989). The general structure, organization, and appearance of Strongyloides free-living females and C. elegans hermaphrodites are similar. Infective L3s, the hypothesised analogue of dauer larvae of free-living nematodes (Hotez et al., 1993) are, like C. elegans dauer larvae, radially constricted with a filariform oesophagus approximately half the length of the larva (Figure 5). These larvae have a tripartite pointed tail which, when viewed with a dissecting microscope, appears like a simple fork (Figure 5); these larvae are highly active in liquid following gentle agitation.

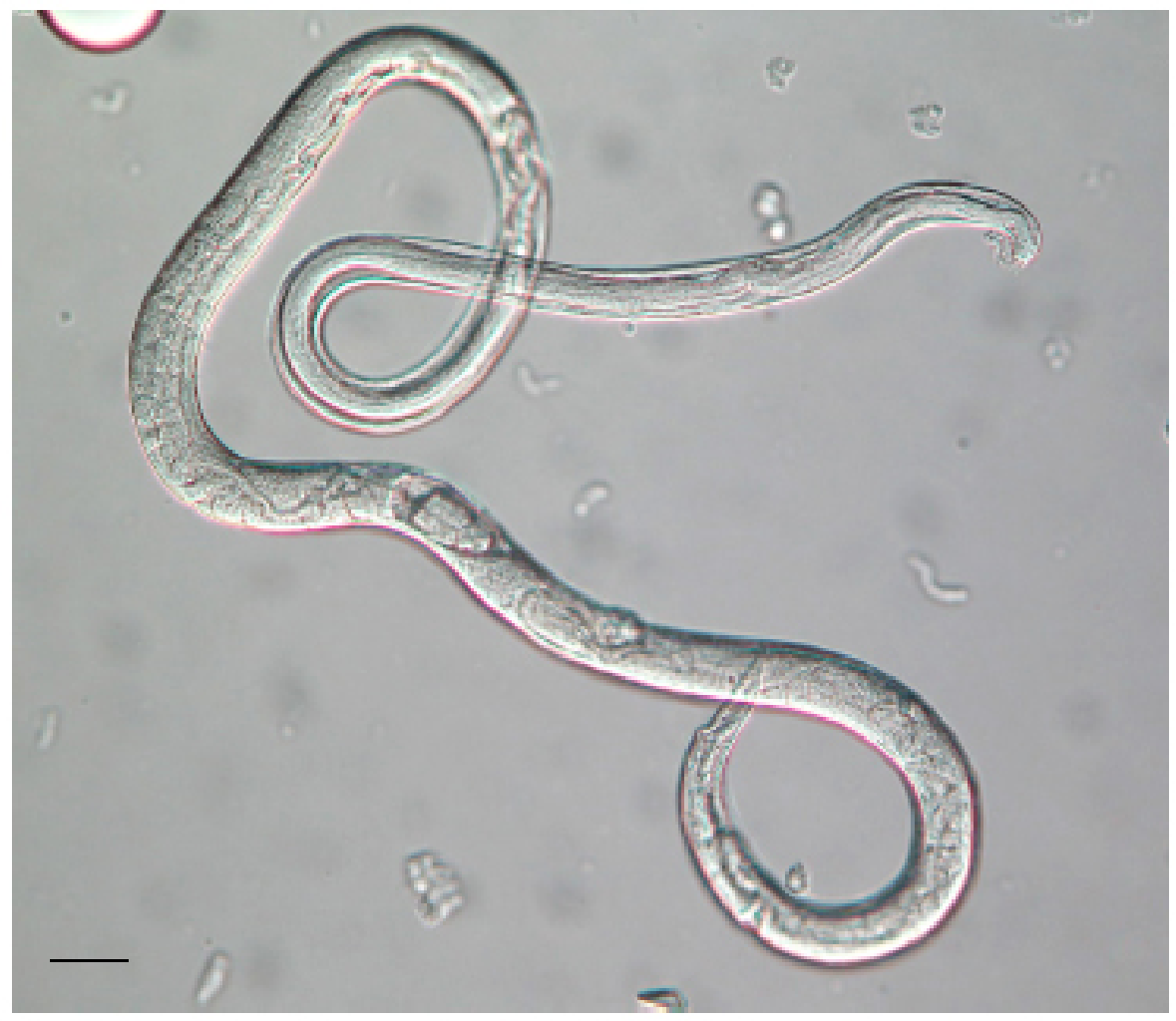

Figure 3. A parasitic female of $S$. ratti. Scale bar $=30 \mu \mathrm{m}$. 


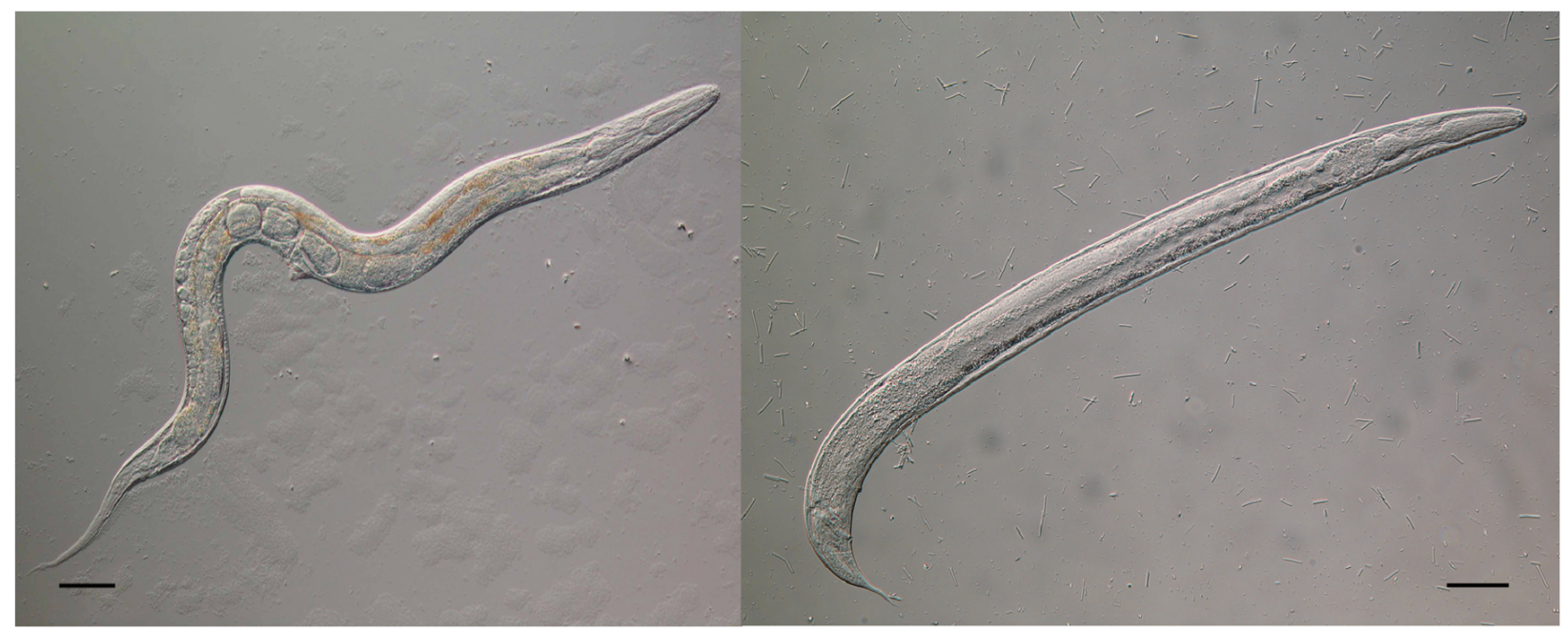

Figure 4. A free-living adult female and male (left and right, respectively) of $\boldsymbol{S}$. ratti. The female is live, the male is fixed. Fixed males characteristically adopt this ventral curve to their tail. Scale bars $=50 \mu \mathrm{m}$.

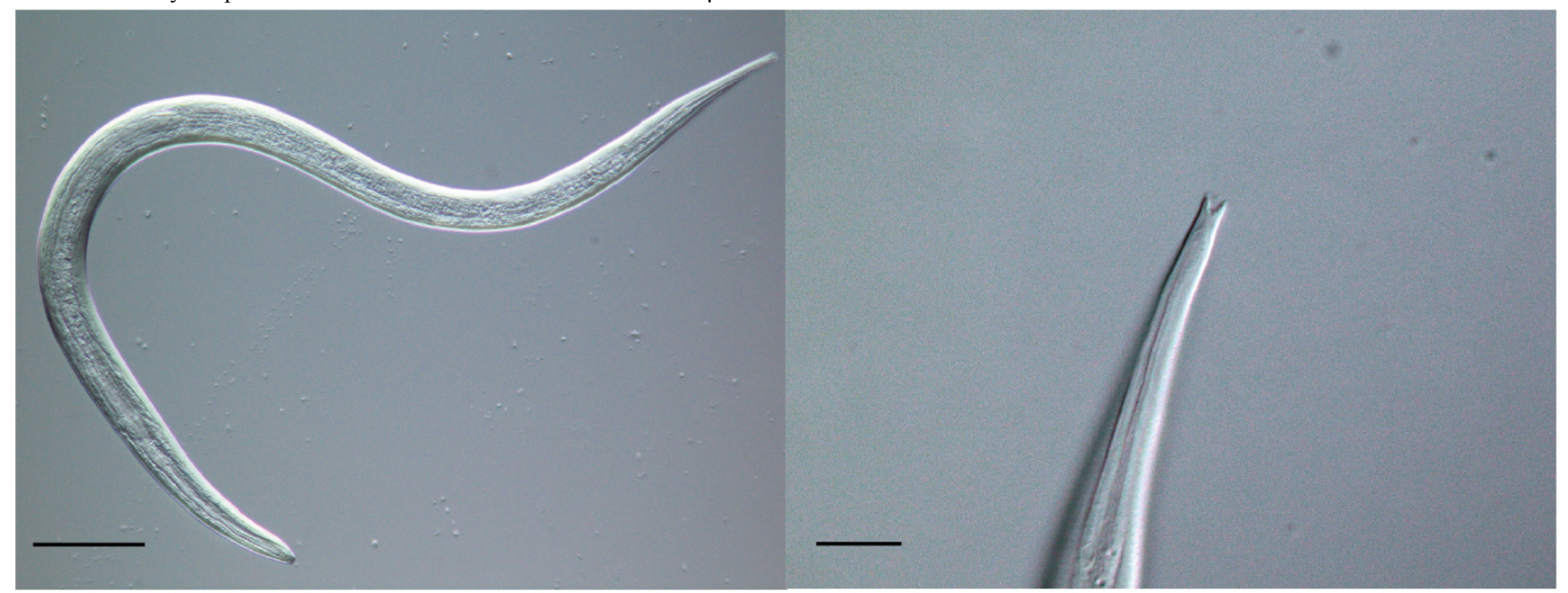

Figure 5. An infective $\mathbf{L 3}$ of $S$. ratti (left, scale bar $=100 \mu \mathrm{m}$ ) showing the forked tail (right, scale bar $=10 \mu \mathrm{m})$.

There are a number of characters used for species identification. For the parasitic females these are the disposition of the ovaries (parallel to or spiralled around the intestine); the en face view of the stoma (Little, 1966); the stage passed in host faeces (i.e., eggs, larvae, or eggs and larvae), and more recently, the morphology of the peri-vulval lateral cuticle (Speare, 1989; Viney and Ashford, 1990). Morphometric comparison of body size and the relative position of various structures is also used extensively. The means of recovery of these parasitic stages (e.g., collection from intestine or from faeces following host anthelminthic therapy), as well as the effects of the host immune response on the morphology of $S$. ratti parasitic females (e.g., Kimura et al., 1999), will reduce the utility of these morphometric approaches.

For the free-living adult males and females morphometrics are also important, as too is the arrangement of the peri-cloacal papillae of the male (Speare, 1989). The forked tail of the infective L3s is a particularly clear diagnostic character for Strongyloides (see Figure 5), which allows easy allows differentiation from other nematodes that may contaminate faecal samples.

\section{The life-cycle}

The life-cycle of Strongyloides is both complicated and somewhat tricky to understand, but also one part of the fascination of the genus. This description is primarily based on the life-cycle of $S$. ratti (a parasite of the rat), which has been extensively studied; some of these details are likely to vary in other species. 
Hosts become infected when free-living infective L3s penetrate the skin. Naturally this occurs by the chance coming together of host skin and larvae, though this is facilitated by dispersal and nictation behaviours of the larvae. In the laboratory this comes about by the deliberate application of infective L3s to host skin or by subcutaneous injection (Tindall and Wilson, 1988). These larvae migrate through the host body such that from 24 hours post infection (p.i.) they are found in the naso-frontal region of the host from where they are, presumably, swallowed to reach the small intestine (Tindall and Wilson, 1988). This naso-frontal route of migration has been most thoroughly determined in S. ratti; in other species of Strongyloides (and other genera of skin-penetrating nematodes) migration through the lungs is also thought to be important. During this migration they moult via an L4 stage so that there are adult parasitic female worms present in the gut from approximately 4 days p.i., with reproduction commencing shortly thereafter, detected by the presence of eggs and/or larvae in the faeces (Kimura et al., 1999).

In the host faeces the eggs hatch to release first-stage larvae (L1) (Figure 6). Larvae are either male or female. Male larvae develop via L2-L4 stages into rhabditiform males. Analogously, female larvae can develop into rhabditiform females. Together, this type of development is known as indirect, sexual, or heterogonic development. The free-living adults mate and the female lays eggs that hatch to release L1s that moult via an L2 into infective filariform L3 stages. All the progeny of the free-living adult generation are female. These infective L3 stages are long lived and can persist in the environment until they encounter a suitable host. Their behaviour is to move away from the host faeces in which they have developed, a behaviour likely to enhance their probability of finding a host. In addition, female L1s that hatch from eggs passed in faeces have an alternative fate, to moult via an L2 into infective L3s. This type of development is known as direct, asexual, or homogonic development. Infective L3s that have developed via the direct or indirect route are, apparently, the same.

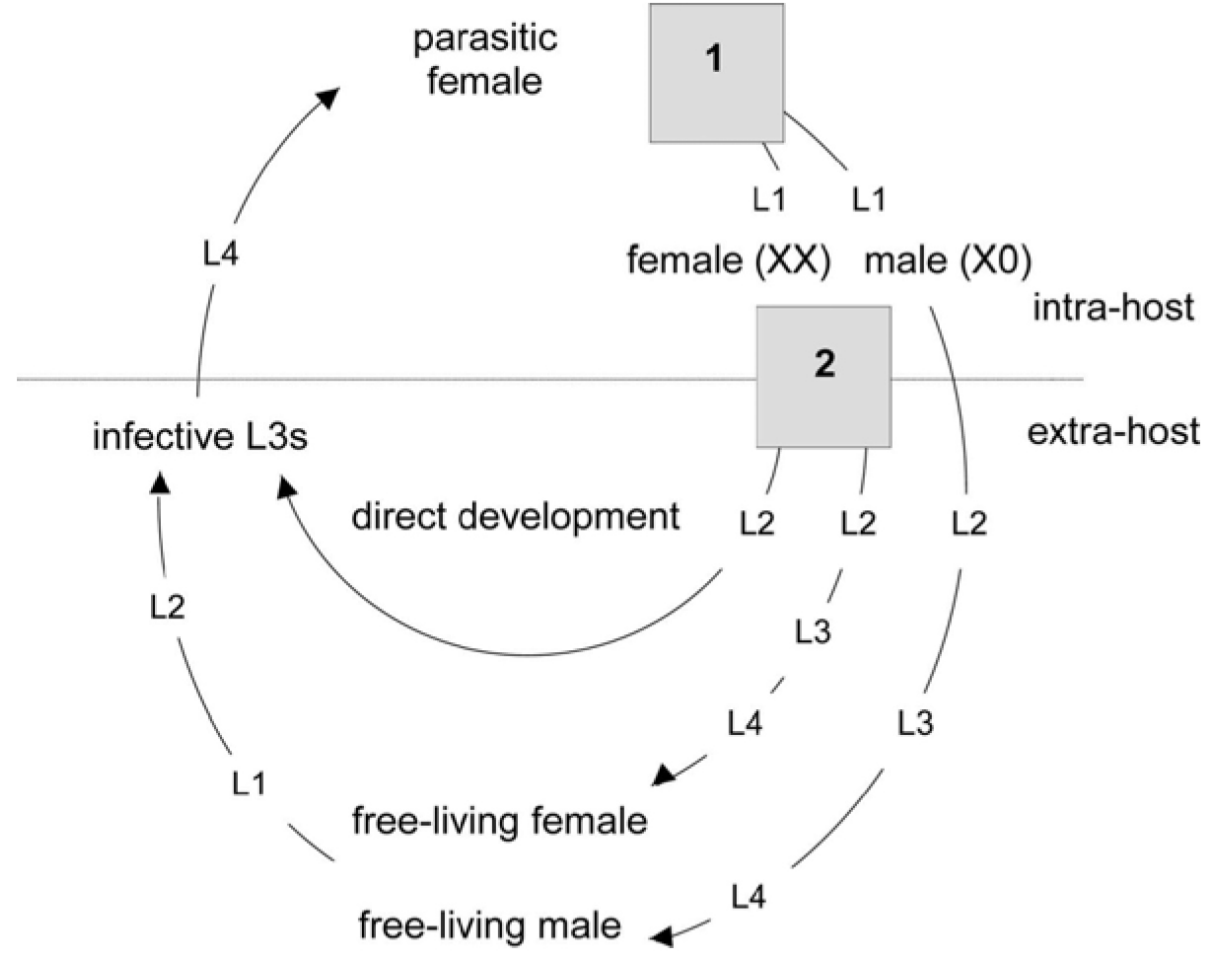

Figure 6. The life-cycle of Strongyloides ratti. The progeny of the parasitic females have two developmental switches (grey boxes): (1) a sex determination event; (2) a female-only developmental switch (after Harvey et al., 2000). Numbered larval stages are shown as L.

For most Strongyloides species only one free-living adult generation occurs. However, up to nine (decreasingly fecund) free-living generations have been observed for $S$. planiceps, though in the same study $S$. stercoralis had only one free-living adult generation (Yamada et al., 1991). Strongyloides therefore differs from its relative Parastrongyloides which has apparently unlimited successive free-living generations (Grant et al., 2006a). 
The free-living adult generation of Strongyloides (and Parastrongyloides) is therefore rather similar to the life-cycle of C. elegans, that is, L1-L4 stages that develop into free-living adults that mate to produce eggs and L1 progeny. However, the major difference is that the progeny of Strongyloides spp. free-living adults develop into infective L3s, the hypothesised analogue of dauer larvae (Hotez et al., 1993).

S. stercoralis can undergo autoinfection, that is, repeated generations of development in the same host individual. Autoinfection appears to be unique to $S$. stercoralis within the genus (and also essentially unique among other genera of gastrointestinal parasites of vertebrates; only Enterobius spp. and Capillaria spp. also have this phenomenon) and largely accounts for it being a serious pathogen of humans. Autoinfection involves accelerated development by larval progeny of parasitic females such that they develop into infective L3s within the gut, which then penetrate directly into the tissues of the primary host. Thus here, the entire life cycle is completed within a host and there are no stages external to the host. Autoinfection may result in dissemination of L3 through many organs and tissues of the host, as well as the establishment of new parasitic females in the gut. In the absence of treatment, subsequent rounds of autoinfection are possible, resulting in fulminant expansion of parasite populations and multi-organ involvement with potentially fatal consequences for the host (Igra-Siegman et al., 1981). Groups at risk of such so-called disseminated S. stercoralis infections include patients who are immunocompromised as a result of corticosteroid therapy, various neoplasms, or infection with the human T lymphotropic virus-1 (Carvalho and Da Fonseca Porta, 2004; Lim et al., 2004; Buofrate et al., 2013).

A prominent and intriguing subgroup of disseminated strongyloidiasis cases are of former far-east prisoners of war (World War II) who now reside in Europe, Australasia, or North America and present with the disease as much as 50 years after leaving the endemic area. Corticosteroid therapy and/or concurrent cancer treatment are common features of these cases (Gill and Bell, 1979; Gill et al., 2004). The onset of disseminated strongyloidiasis decades after the last possible exposure to the parasite is extremely serious for elderly patients. But, this also makes clear a salient feature of the infection biology of $S$. stercoralis, namely the capacity to maintain exceedingly chronic infections in hosts. Such hyperchronic infections usually go undiagnosed due to the paucity or absence of larvae in the faeces. Alternative hypotheses for the chronicity of these infections are that either there are dormant larvae in the tissues or senescent non-reproductive female worms in the intestine, with immunosuppression triggering either reactivation of dormant larvae or resumption of egg laying by barren parasitic females. Data from studies conducted over a relatively short time frame (77 days) in experimentally infected dogs favour the latter mechanism involving resumed oviposition by barren female worms (Mansfield et al., 1996). The importance of people with chronic asymptomatic strongyloidiasis as a group at risk of disseminated hyperinfection has recently been emphasised (Caumes and Keystone, 2011).

Hypobiosis or dormancy of Strongyloides L3s may or may not be central to the maintenance of chronic infections, but it is key to another mode of transmission: transmammary transmission. There is evidence of transmammary transmission in S. ratti and S. venezuelensis in rats (Nolan and Katz, 1981; Kawanabe et al., 1988), S. stercoralis in dogs (Shoop et al., 2002), S. fuelleborni kellyi in humans (Ashford et al., 1992), and several species affecting livestock including $S$. ransomi in swine (Stewart et al., 1976), S. westeri in horses (Lyons, 1994), and $S$. papillosus in ruminants (Moncol and Grice, 1974). Infective L3s transmitted by the transmammary route presumably arrest their development and migration in the mammary glands, and then re-activate at lactation. Transmammary transmission also occurs in other parasitic nematodes that have a phase of within-host tissue migration during their life cycles, including ascarid roundworms and hookworms (Stone and Smith, 1973; Shoop and Corkum, 1987).

\section{Sex determination and genetics of the life-cycle}

Sex determination in S. ratti is an XX/X0, female/male system. XX parasitic females produce XX female and X0 male larvae (Harvey and Viney, 2001). It is not known whether this system of sex determination relies on the ratio of X chromosomes to autosomes, as occurs in C. elegans, or whether it relies simply on the absolute number of $\mathrm{X}$ chromosomes. The male larvae develop into free-living males only. The XX female larvae have an environmentally determined choice, between developing into free living adult females or into infective L3s. These XX infective L3s develop into parasitic females directly. XX free-living females and X0 free-living males mate and produce XX, female-only infective L3 progeny, which can develop into parasitic females (Harvey and Viney, 2001). Therefore, as a consequence of some process acting either during male gametogenesis or at fertilisation, all progeny inherit the paternal X chromosome (Figure 6). In S. papillosus there is a male-specific chromatin diminution event, which functionally generates an XX/XO system in this species too (Nemetschke et al., 2010a). 
The sex ratio of $S$. ratti is highly variable between different isolates, ranging from apparently nearly all female to 20-50\% male and this can change over time (see Section 7) (Viney et al., 1992; Harvey et al., 2000). This is in contrast to the generally highly hermaphrodite-biased sex ratio of C. elegans (in the absence of matng with males), which perhaps suggests that the mechanisms that control the sex ratio in these two genera are different (Harvey and Viney, 2001).

The parasitic females of $S$. ratti reproduce parthenogenetically (Viney, 1994). This parthenogenesis is genetically mitotic, as shown by the absence of allelic segregation. Thus, the female progeny of a parasitic female are identical to each and to their mother. Formally, this parthenogenesis may occur either by mitotic parthenogenesis or by types of meiotic parthenogenesis (in which meiosis is modified to restore the diploid state) in which allelic segregation does not occur (Hughes, 1989). Single parasitic female infections can therefore give rise to isofemale lines (Viney et al., 1992). The free-living adult generation of $S$. ratti and S. papillosus reproduces by conventional sexual reproduction (Viney et al., 1993; Eberhardt et al., 2007). The maximum life-time fecundity of $S$. ratti free-living females is less than 40 (Gardner et al., 2004).

There has been extensive cytological investigation of Strongyloides, investigating both sex determination and means of reproduction of the parasitic and free-living adult generations (e.g., Triantaphyllou and Moncol, 1977; Albertson et al., 1979). The genetic analysis of S. ratti and S. papillosus and the cytological analyses of many species do not agree. This suggests that the carefully observed and recorded cytology may not reliably reveal the genetics of Strongyloides.

\section{Controlling the life-cycle}

The extent to which indirect (or heterogonic) and direct (or homogonic) development occur in the free-living phases of the Strongyloides life-cycle depends on the sex ratio of the free-living generation and on a range of environmental conditions. Again, these phenomena are most thoroughly understood for $S$. ratti. For $S$. ratti, the developmental choice of XX female larvae is affected by environmental conditions. For example, the temperature at which faeces containing developing larvae is held external to the host affects development, such that female larvae preferentially develop into free-living adult females (indirect development) at higher temperatures (Viney, 1996). It is probable that many other environmental factors (e.g., food quantity and quality) may have similar effects. There has been extensive investigation of a wide range of factors for a number of species (Arizono, 1976; Moncol and Triantaphyllou, 1978; Minematsu et al., 1989) (Figure 6). These phenomena have been investigated in the related genus Parastrongyloides (Grant et al., 2006a).

For $S$. ratti, the immune status of the host from which developing larvae are passed also affects the development of the free-living larvae. This occurs in two ways. First, XX female larvae preferentially develop into adult free-living females (indirect development) when passed from hosts mounting an anti-S. ratti immune response (Gemmill et al., 1997; Harvey et al., 2000). In addition, the sex ratio of larvae passed from hosts mounting such an immune response becomes more male biased (Harvey et al., 2000). The combined effect of the host immune response is therefore that comparatively more free-living adult males and females develop. In $S$. stercoralis infections of humans co-infected with HIV, there is also a relationship between an individual's immune status and the developmental route of their S. stercoralis infection (Viney et al., 2004).

There is yet further complexity. XX female larvae are comparatively more sensitive to environmental temperature (measured as their developmental response) when passed from hosts mounting an anti-S. ratti response. The effect of the host immune response and its interaction with environmental conditions is that indirect development is favoured by larvae passed from hosts mounting an anti-S. ratti immune response (Harvey et al., 2000).

There are some interesting implications of this sophisticated control of these developmental choices. Firstly, the mechanism by which an apparently environmental feature (the host immune response) affects the sex ratio of the progeny is not known. It is also not clear how developing larvae measure the host immune response and/or how this measurement is 'remembered' through time, since the host immune response is, presumably, measured within the host, yet the developmental consequences occur later and outside of the host (Viney, 2002; Crook and Viney, 2005).

For $S$. ratti, there is extensive inter-isolate variation in the predominant nature of the development of the free-living generation. For example, isolates of $S$. ratti from the UK show an almost $100 \%$ homogonic development (Viney et al., 1992). Such inter-isolate variation implies that there is extensive variation in the sex ratio of the progeny of the parasitic female generation and/or in the sensitivity of larvae to environmental conditions. The degree of direct and indirect development can be artificially selected (Viney, 1996). 
The hypothesised homology between the dauer larvae of free-living nematodes and infective L3 stages of parasitic nematodes has been noted before (Hotez et al., 1993; Riddle and Albert, 1997). The homology is particularly attractive with Strongyloides, because of the similarity between the free-living life-cycle of Strongyloides and that of $C$. elegans. This analogy has been investigated. For S. stercoralis, laser ablation of amphidial neurons has identified the two that are necessary to control the female developmental decision. These amphidial neurons were identified by analogy with C. elegans (Ashton et al., 1995; Ashton and Schad, 1996; Ashton et al., 1998).

The role of daf-7 in controlling the dauer-formation decision of C. elegans (Ren et al., 1996) has promoted investigation of putative homologous genes in parasitic nematodes, including $S$. ratti and $S$. stercoralis. However, based on comparison of the life-cycle stage expression pattern, this has not directly supported the parasitic nematode infective L3 vs. free-living nematode dauer larvae analogy (Crook et al., 2005; Massey et al., 2005; Viney et al., 2005). Insulin-like signalling also influences dauer larval development in C. elegans, and evidence from genetic (Castelletto et al., 2009) and pharmacological (Stoltzfus et al., 2012a) studies indicates that it may similarly regulate the development of infective larvae in S. stercoralis. In regulating dauer larva development in C. elegans, both insulin-like and TGF- $\beta$-like (daf-7) signalling converge on a steroid nuclear hormone (NHR) signalling system involving the DAF-12 NHR and its steroid ligands the dafachronic acids (Motola et al., 2006). Recent findings support a similar NHR-regulated system affecting formation and development of infective larvae in $S$. stercoralis (Wang et al., 2009) and S. papillosus (Ogawa et al., 2009).

\section{Maintaining the life-cycle}

Strongyloides is surprisingly easy to maintain in the laboratory. To grow the free-living generation, faeces (collected from an infected laboratory animal) simply need to be maintained damp and at a slightly elevated temperature. For some host species (carnivores, primates, or anything with particularly smelly faeces) the faecal material should be mixed with wetted activated charcoal. There are many different ways in which the faeces can be cultured, with the 'sophistication' of these different methods simply seeking to allow the larval and adult stages to separate themselves from faecal material. The methods for S. stercoralis are given in detail in Strongyloides stercoralis: a model for translational research on parasitic nematode biology. Larvae recovered from faecal cultures can also be maintained on modified NGM agar plates (Gardner et al., 2004; Li et al., 2006).

Infective L3s recovered from faecal cultures can be used to infect host animals. This can be done 'naturally' by applying larvae to dampened skin or fur (Tindall and Wilson, 1988). More routinely, infective L3s can be inoculated subcutaneously by injection (e.g., Wilkes et al., 2004). The eggs and larvae of Strongyloides passed in faeces are susceptible to desiccation. This has two consequences. First, if infected hosts are maintained in dry conditions, then between-animal transmission within an animal house will not occur. Second, when collecting faeces with which to initiate faecal cultures, either freshly deposited faeces must be collected or cages must be arranged so that faeces collect onto a damp surface.

\section{The parasitic phase of the life-cycle}

The biology of the parasitic phase, principally the parasitic females, is the least well known, largely because of the relative difficulty of working with these stages. The females are embedded in the mucosa of the small intestine, often close to the crypts of Lieberkühn (Dawkins et al., 1983). The females migrate through the mucosa, leaving trails of eggs (Figure 2) (Grove et al., 1987). These eggs then, presumably passively, make their way to the gut lumen, before being passed out of the host in faeces either before and/or shortly after hatching depending on the species. Parasitic females are usually concentrated in the proximal part of the small intestine.

Infected hosts make an anti-Strongyloides immune response against both larvae migrating from the site of infection to the intestine, and against intestinal parasitic females. The nature of this response differs between these sites and stages of Strongyloides (Bell et al., 1981; Korenaga et al., 1983). The host immune response has deleterious effects on the parasitic females. Parasitic females become shorter, their fecundity is reduced, and they become more posteriorly positioned in the host intestine as an anti-Strongyloides immune response develops (Kimura et al., 1999; Wilkes et al., 2004). These effects either do not occur in immunodeficient hosts (e.g., in nude rats which are athymic and, hence, have no T-cell arm of the immune system) or are reversible if the host is immunosuppressed (Gemmill et al., 1997; Viney et al., 2006). In S. ratti infections the host immune response brings about density-dependent effects on the survival and reproduction of the parasitic stages (Paterson and Viney, 2002), which is ultimately due to a parasite dose-dependent change in the quality of the host immune response (Bleay et al., 2007; Wilkes et al., 2007). 
Ultimately these effects of the host immune response result in most experimental animals losing their infections after a period of time. For $S$. ratti in rats, readily detectable patent infections last for approximately a month, though some worms persist for up to about 10 weeks (Kimura et al., 1999; Wilkes et al., 2004). S. ratti infections of nude rats last for approximately a year (403 days), with the parasitic females dying of senescence (Gardner et al., 2006). The maximum lifespan of $S$. ratti free-living females is five days (Gardner et al., 2004); thus, the two female forms of the $S$. ratti life-cycle have an 80 -fold difference in their maximum lifespan (Gardner et al., 2006).

A common strategy by which parasitic nematodes enhance their own survival in hosts is to, in some way, immunomodulate their host immune responses. This phenomenon has now also been found for Strongyloides spp. in rodent models (Negrao-Correa et al., 2003; Hartmann et al., 2012).

For S. stercoralis, host immunosuppression is used both to enhance the longevity and intensity of infection, and to facilitate experimental autoinfection (Grove et al., 1983; Strongyloides stercoralis: a model for translational research on parasitic nematode biology).

Strongyloides infections can readily be treated with anthelminthic drugs both therapeutically and experimentally. The drug of choice is thiabendazole, though ivermectin is also effective, especially for disseminated infection (Grove, 1989b; Conway et al., 1995; Turner et al., 2005).

\section{Life-cycle plasticity}

A common feature of the life-cycle of parasitic nematodes is that there are phases of the life-cycle in one host species that alternate with phases either outside of a host or in a second (or third) host species. This means that parasitic nematodes live multi-facetted lives. Life-cycle stages that are specific to one host species, or to the external environment, differ by the very fact that they are adapted to these different niches (Viney and Cable, 2011; Viney and Diaz, 2012). Strongyloides spp. is no different in this respect. However, the genetics of its life-cycle gives an unrivaled opportunity to address questions of the mechanism of these processes. Thus, the parasitic adult female stage is genetically identical to the free-living adult female stage, such that differences between these two stages can be used as a model to understand the basis of parasitism. Such a comparison in this life-cycle is particularly powerful, especially compared to other parasitic nematode life-cycles where, typically, a parasitic phase of the life-cycle consists of adult worms, whereas free-living stages consist of larval stages. Thus, in these settings any comparison of parasitic and free-living stages is also confounded by an adult and larval comparison. The recent interrogation of the Strongyloides spp. genome (Section 11), including the construction of a genetic map for S. ratti (Nemetschke et al., 2010b), is now facilitating these analyses (e.g., Spinner et al., 2012).

\section{Genomics}

The genome sequences of $S$. ratti, S. venezuelensis, S. papillosus and S. stercoralis (and of the relative Parastrongyloides trichosuri) have been determined. The availability of isofemale lines of some of these species (or other approaches to inbreeding) has been very important in efficiently assembling these genomes. For $S$. ratti (for which the genome sequence is most complete and has the best annotation) the genome is $43 \mathrm{Mbp}$ (thus, less than half the size of the C. elegans genome) with a high (79\%) AT content, predicted to code for approximately 12,000 genes. Large scale transcriptomic approaches with $S$. stercoralis have been used, particularly aimed at discovering genes used in the developmental control of the S. stercoralis life-cycle (Stoltzfus et al., 2012b).

This genomic work has built on previous expressed sequence tag (EST) analyses of $S$. stercoralis (free-living L1 and infective L3s) and S. ratti (free-living L1, L2, mixed free-living adults and infective L3s, parasitic females) (Mitreva et al., 2004; Thompson et al., 2005). For $S$. ratti there has been fairly extensive microarray analysis, comparing different life-cycle stages, different immune environments and differently selected lines (e.g., Thompson et al., 2006; Thompson et al., 2008; Thompson et al., 2009; O'Meara et al., 2010).

While determining the genome sequence of these species is a key step, further exploitation of the genome also requires genetic tools. To this end transgenic methods have very recently been developed for $S$. stercoralis, and for the related nematode P. trichosuri (Grant et al., 2006b; Li et al., 2006; Li et al., 2011; Strongyloides stercoralis: a model for translational research on parasitic nematode biology). Chromosomal integration of transgenes by the piggyBac transposon system has enabled derivation of the first stable, transgene expressing lines of $S$. ratti (Shao et al., 2012). 


\section{Acknowledgments}

We would like to thank Simon Harvey, Gerhard Schad and Fiona Thompson for their comments on earlier versions of this chapter, David Tricker with the figures and Matt Berriman, Nancy Holroyd, and Vicky Hunt for access to unpublished genomic sequence. MEV would like to thank MRC, NERC, BBSRC and The Wellcome Trust for financial support. JBL gratefully acknowledges financial support from the US National Institutes of Health (grants AI50688, AI22662 and RR02512) and the Ellison Medical Foundation (ID-IA-0037-02).

\section{References}

Albonico, M., Crompton, D.W.T., and Savioli, L. (1999). Control strategies for human intestinal nematode infections. Adv. Parasitol. 42, 277-341. Abstract Article

Albertson, D.G., Nwaorgu, O.C., and Sulston, J.E. (1979). Chromatin diminution and a chromosomal mechanism of sexual differentiation in Strongyloides papillosus. Chromosoma 75, 75-87. Abstract Article

Anderson, R.C. (2000). Nematode parasites of vertebrates: their development and transmission (Oxford: CABI Publishing). Article

Arizono, N. (1976). Studies on the free-living generations of Strongyloides planiceps Rogers 1943. 1. Effects of quantity of food on population density on the developmental types. Jap. J. Parasitol. 25, 274-282.

Ashford, R.W., and Barnish, G.B. (1989). Strongyloides fuelleborni and similar parasites in animals. In: Strongyloidiasis a major roundworm infection of man, D.I. Grove, ed. (London: Taylor and Francis), pp. $271-286$. Abstract

Ashford, R.W., Barnish, G., and Viney, M.E. (1992). Strongyloides fuelleborni kellyi: Infection and disease in Papua New Guinea. Parasitol. Today 8, 314-318. Abstract Article

Ashton, F.T., and Schad, G.A. (1996). Amphids in Strongyloides stercoralis and other parasitic nematodes. Parasitol. Today 12, 187-194. Abstract Article

Ashton, F.T., Bhopale, V.M., Fine, A.E., and Schad, G.A. (1995). Sensory neuroanatomy of a skin-penetrating nematode parasite Strongyloides stercoralis. I. Amphidial neurons. J. Comp. Neurol. 357, 281-295. Abstract Article

Ashton, F.T., Bhopale, V.M., Holt, D., Smith, G., and Schad, G.A. (1998). Developmental switching in the parasitic nematode Strongyloides stercoralis is controlled by the ASF and ASI amphidial neurons. J. Parasitol. 84, 691-695. Abstract Article

Bavay, A. (1876). Sur l'Anguillule stercorale. (Presentée par M.P. Gervias). C.R. Hebd. Séances Acad. Sci. 83, 694-696.

Bavay, A. (1877). Sur l'Anguillule intestinale (Anguillula intestinalis), nouveau ver nématoïde, trouvé par le Dr. Normand chez les malades atteints de diarrhée de Cochinchine. (Presentée par M.P. Gervias). C.R. Hebd. Séances Acad. Sci. 84, 266-268.

Bell, R.G., Adams, L.S., and Gerb, J. (1981). Strongyloides ratti: Dissociation of the rat's protective immunity into systemic and intestinal components. Exp. Parasitol. 52, 386-395. Abstract Article

Blaxter, M.L., De Ley, P., Garey., J.R., Liu, L.W., Scheldeman, P., Vierstraete, A., Vanfleteren, J.R., Mackey, L.Y., Dorris, M., Frisse, L.M., Vida, J.T., and Thomas, W.K. (1998). A molecular evolutionary framework for the phylum Nematoda. Nature 392, 71-75. Abstract Article

Bleay, C., Wilkes C.P., Paterson S., and Viney, M.E. (2007). Density-dependent immune responses against the gastrointestinal nematode Strongyloides ratti. Int J. Parasitol. 37, 1501-1509. Abstract Article

Buofrate, D., Requena-Mendez, A., Angheben, A., Munoz, J., Gobbi, F., Van Den Ende, J., and Bisoffi, Z. (2013). Severe strongyloidiasis: a systematic review of case reports. BMC Infect. Dis. 13, 78. Abstract Article 
Carvalho E.M., Da Fonseca Porto, A. (2004). Epidemiological and clinical interaction between HTLV-1 and Strongyloides stercoralis. Parasite Immunol. 26, 487-497. Abstract Article

Castelletto, M.L., Massey, H.C., Jr., and Lok, J.B. (2009). Morphogenesis of Strongyloides stercoralis infective larvae requires the DAF-16 ortholog FKTF-1. PLoS Pathog. 5, e1000370. Abstract Article

Caumes, E., and Keystone, J.S. (2011). Acute strongyloidiasis: a rarity. Chronic strongyloidiasis: a time bomb! J. Trav. Med. 18, 71-72. Abstract Article

Conway, D.J., Lindo, J.F., Robinson, R.D., and Bundy, D.A.P. (1995). Towards effective control of Strongyloides stercoralis. Parasitol. Today 11, 420-424. Article

Crompton, D.W.T. (1987). Human helminthic populations. In Bailliere's Clinical Tropical Medicine and Communicable Diseases, Z.S. Pawlowski, ed. (London: Academic Press), pp. 489-510.

Crook, M., and Viney, M.E. (2005). The effect of non-immune stresses on the development of Strongyloides ratti. Parasitology 131, 383-392. Abstract Article

Crook, M., Thompson, F.J., Grant, W.N., and Viney M.E. (2005). The role of daf-7 in the development of Strongyloides ratti and Parastrongyloides trichosuri. Mol. Biochem. Parasitol. 139, 213-223. Abstract Article

Dawkins, H.J.S., Robertson, T.A., Papadimitriou, J.M., and Grove, D.I. (1983). Light and electron microscopical studies of the location of Strongyloides ratti in the mouse intestine. Z. Parasitenkd. 69, 357-370. Abstract Article

Dorris, M., Viney, M.E., and Blaxter, M.L. (2002). Molecular phylogenetic analysis of the genus Strongyloides and related nematodes. Int. J. Parasitol. 32, 1507-1517. Abstract Article

Eberhardt, A.G., Mayer, W.E. and Streit, A. (2007). The free-living generation of the nematode Strongyloides papillosus undergoes sexual reproduction. Int. J. Parasitol. 37, 989-1000. Abstract Article

Fisher, M.C., and Viney, M.E. (1998). The population genetic structure of the facultative sexual parasitic nematode Strongyloides ratti in wild rats. Proc. Biol. Sci. 265, 703-709. Abstract Article

Gardner, M.P., Gems, D., and Viney, M.E. (2004). Aging in a very short-lived nematode. Exp. Gerontol. 39, 1267-1276. Abstract Article

Gardner, M.P., Gems, D., and Viney, M.E. (2006). Extraordinary plasticity in aging in Strongyloides ratti implies a gene-regulatory mechanism of lifespan evolution. Aging Cell 5, 315-323. Abstract Article

Gemmill, A.W., Viney, M.E., and Read, A.F. (1997). Host immune status determines sexuality in a parasitic nematode. Evolution 51, 393-401. Article

Genta, R.M., and Caymmi Gomes, M.C. (1989). Pathology. In Strongyloidiasis a major roundworm infection of man, D.I. Grove, ed. (London: Taylor and Francis), pp. 105-132.

Gill, G.V., and Bell, D.R. (1979). Strongyloides stercoralis infection in former Far East prisoners of war. Br. Med. J. 2, 572-574. Abstract Article

Gill, G.V., Beeching, N.J., Khoo, S., Bailey, J.W., Partridge, S., Blundell, J.W., and Luksza, A.R. (2004). A British Second World War veteran with disseminated strongyloidiasis. Trans. R. Soc. Trop. Med. Hyg. 98, 382-386. Abstract Article

Grant, W.N., Stasiuk, S., Newton Howes, J., Ralston, M., Bisset, S.A., Heath, D.D., and Shoemaker, C.B. (2006a). Parastrongyloides trichosuri, a nematode of mammals that is uniquely suited to genetic analysis. Int. J. Parasitol. 35, 453-466. Abstract Article

Grant, W.N., Skinner, S.J.M., Newton Howes, J., Grant, K., Shuttleworth, G., Heath, D.D., and Shoemaker, C.B. (2006b). Heritable transgenesis of Parastrongyloides trichosuri: a nematode parasite of mammals. Int. J. Parasitol. 36, 475-483. Abstract Article 
Grassi, G.B. (1879). Sovra l'Anguillula intestinale. Rendiconti del Reale Istituto Lombardo di Scienze e Lettere, Milano, second series 12, 228-233.

Grove, D.I. (1989a). Clinical manifestations. In Strongyloidiasis a major roundworm infection of man, D.I. Grove, ed. (London: Taylor and Francis), pp. 155-174.

Grove, D.I. (1989b). Treatment. In Strongyloidiasis a major roundworm infection of man, D.I. Grove, ed. (London: Taylor and Francis), pp. 199-231.

Grove, D.I., Heenan, P.J., and Northern, C. (1983). Persistent and disseminated infections with Strongyloides stercoralis in immunosuppressed dogs. Int. J. Parasitol. 13, 483-490. Abstract Article

Grove, D.I., Warton, A., Yu, L.L., Northern, C., and Papadimitriou, J.M. (1987). Light and electron microscopical studies of the location of Strongyloides stercoralis in the jejunum of the dog. Int. J. Parasitol. 17, 1257-1265. Abstract Article

Hartmann, W., Eschbach, M-L., and Breloer, M. (2012). Strongyloides ratti infection modulates B and T cell responses to third party antigens. Exp. Parasit. 132, 69-75. Abstract Article

Harvey, S.C., Gemmill, A.W., Read, A.F., and Viney, M.E. (2000). The control of morph development in the parasitic nematode Strongyloides ratti. Proc. Biol. Sci. 267, 2057-2063. Abstract Article

Harvey, S.C., and Viney, M.E. (2001). Sex determination in the parasitic nematode Strongyloides ratti. Genetics 158, 1527-1533. Abstract

Hira, P.R., and Patel, B.G. (1980). Human strongyloidiasis due to the primate species Strongyloides fuelleborni. Trop. Geogr. Med. 32, 23-29. Abstract

Hotez, P., Hawdon, J., and Schad, G.A. (1993). Hookworm larval infectivity, arrest and amphiparatenesis: The Caenorhabditis elegans daf-c paradigm. Parasitol. Today 9, 23-26. Abstract Article

Hughes, R.N. (1989). A functional biology of clonal animals (London: Chapman and Hall).

Igra-Siegman, Y., Kapila, R., Sen, P., Kaminski, Z.C., and Louria D.B. (1981). Syndrome of hyperinfection with Strongyloides stercoralis. Rev. Infect. Dis. 3, 397-407. Abstract Article

Kawanabe, M., Nojima, H., and Uchikawa, R. (1988). Transmammary transmission of Strongyloides ratti. Parasitol. Res. 75, 50-56. Abstract Article

Kimura, E., Shinotoku, Y., Kadosaka, T., Fujiwara, M., Kondo, S., and Itoh, M. (1999). A second peak of egg excretion in Strongyloides ratti-infected rats: its origin and biological meaning. Parasitology 119, 221-226. Abstract Article

Korenaga, M., Nawa, Y., Mimori, T., and Tada, I. (1983). Effects of preintestinal larval antigenic stimuli on the generation of intestinal immunity in Strongyloides ratti infection in rats. J. Parasitol. 69, 78-82. Abstract Article

Li., X., Massey, H.C., Nolan, T.J., Schad, G.A., Kraus, K., Sundaram, M., and Lok, J.B. (2006). Successful transgenesis of the parasitic nematode Strongyloides stercoralis requires endogenous non-coding control elements. Int. J. Parasitol. 36, 671-679. Abstract Article

Li, X., Shao, H., Junio, A., Nolan, T.J., Massey, H.C., Jr., Pearce, E.J., Viney, M.E., and Lok, J.B. (2011). Transgenesis in the parasitic nematode Strongyloides ratti. Mol. Biochem. Parasitol. 179, 114-119. Abstract Article

Lim, S., Katz, K., Krajden, S., Fuksa, M., Keystone, J.S., and Kain K.C. (2004). Complicated and fatal Strongyloides infection in Canadians: risk factors, diagnosis and management. CMAJ 171, 479-484. Abstract Article

Little, M.D. (1966). Comparative morphology of six species of Strongyloides (Nematoda) and redefinition of the genus. J. Parasitol. 52, 69-84. Abstract Article 
Lyons, E.T. (1994). Vertical transmission of nematodes: Emphasis on Uncinaria lucasi in northern fur seals and Strongyloides westeri in equids. J. Helmin. Soc. Wash. 61, 169-178.

Mackerras, M.J. (1959). Strongyloides and Parastrongyloides (Nematoda: Rhabdiasoidea) in Australian marsupials. Aust. J. Zool. 7, 87-104 Article

Mansfield, L.S., Niamatali, S., Bhopale, V., Volk, S., Smith, G., Lok, J.B., Genta, R.M., and Schad, G.A. (1996). Strongyloides stercoralis: maintenance of exceedingly chronic infections. Am. J. Trop. Med. Hyg. 55, 617-624. Abstract

Massey, H.C., Castelletto, M.L., Bhopale, V.M., Schad, G.A., and Lok, J.B. (2005). Sst-tgh-1 from Strongyloides stercoralis encodes a proposed ortholog of daf-7 in Caenorhabditis elegans. Mol. Biochem. Parasitol. 142, 116-120. Abstract Article

Minematsu, T., Mimori, T., Tanaka, M., and Tada, I. (1989). The effect of fatty-acids on the developmental direction of Strongyloides ratti first stage larvae. J. Helminthol. 63, 13-17. Abstract Article

Mitreva, M., McCarter, J.P., Martin, J., Dante, M., Wylie, T., Chiapelli, B., Pape, D., Clifton, S.W., Nutman, T.B., and Waterson R.H. (2004). Comparative genomics of gene expression in the parasitic and free-living nematodes Strongyloides stercoralis and Caenorhabditis elegans. Genome Res. 14, 209-220. Abstract Article

Moncol, D.J., and Grice, M.J. (1974). Transmammary passage of Strongyloides papillosus in the goat and sheep. Proc. Helmin. Soc. Wash. 41, 1-4.

Moncol, D.J., and Triantaphyllou, A.C. (1978). Strongyloides ransomi: Factors influencing the in vitro development of the free-living generation. J. Parasitol. 64, 220-225. Abstract Article

Morgan, D.O. (1928). Parastrongyloides winchesi gen. et sp. nov. A remarkable new nematode parasite of the mole and the shrew. J. Helminthol. 6, 79-86. Article

Motola, D.L., Cummins, C.L., Rottiers, V., Sharma, K.K., Li, T., Li, Y., Suino-Powell, K., Xu, H.E., Auchus, R.J., Antebi, A., and Mangelsdorf, D.J. (2006). Identification of ligands for DAF-12 that govern dauer formation and reproduction in C. elegans. Cell 124, 1209-1223. Abstract Article

Negrao-Correa, D., Silveira, M.R., Borges, C.M., Souza, D.G., and Teixeira, M.M. (2003) Changes in pulmonary function and parasite burden in rats infected with Strongyloides venezuelensis concomitant with induction of allergic airway inflammation. Infect. Imm. 71, 2607-2614. Abstract Article

Nemetschke, L., Eberhardt, A.G., Hertzberg, H., and Streit, A. (2010a). Genetics, chromatin diminution, and sex chromosome evolution in the parasitic nematode genus Strongyloides. Curr. Biol. 20, 1687-1696. Abstract Article

Nemetschke L., Eberhardt A.G., Viney, M.E., and Streit, S. (2010b). A genetic map of the animal-parasitic nematode Strongyloides ratti. Mol. Biochem. Parasitol. 169, 124-127. Abstract Article

Nolan, T.J., and Katz, F.F. (1981). Transmammary transmission of Strongyloides venezuelensis (Nematoda) in rats. Proc. Helmin. Soc. Wash. 48, 8-12.

O'Meara, H., Barber, R., Mello, L.V., Sangaralingam, A., Viney, M.E., and Paterson, S. (2010). Response of the Strongyloides ratti transcriptome to host immunological environment. Int. J. Parasit. 40, 1609-1617. Abstract Article

Ogawa, A., Streit, A., Antebi, A., and Sommer, R.J. (2009). A conserved endocrine mechanism controls the formation of dauer and infective larvae in nematodes. Curr. Biol. 19, 67-71. Abstract Article

Pampiglione, S., and Ricciardi, M.L. (1972). Geographic distribution of Strongyloides fuelleborni in humans in tropical Africa. Parasitologia 14, 329-338.

Paterson, S., and Viney, M.E. (2002). Host immune responses are necessary for density-dependence in nematode infections. Parasitol. 125, 283-292. Abstract Article 
Ren, P., Lim, C-S., Johnsen, R., Albert, P.S., Pilgrim, D., and Riddle, D.L. (1996). Control of C. elegans larval development by neuronal expression of a TGF- $\beta$ homolog. Science 274, 1389-1391. Abstract Article

Requena-Mendez, A., Chiodini, P., Bisoffi, Z., Buonfrate, D, Gotuzzo, E., and Munoz, J. (2013). The laboratory diagnosis and follow up of strongyloidiasis: A systematic review, PLoS Neg. Trop. Dis. 7, e2002. Abstract Article

Riddle, D.L., and Albert, P.S. (1997). Genetic and environmental regulation of dauer larva development. In $C$. elegans II, D.L. Riddle, T. Blumenthal, B.J. Meyer, J.R. Priess, eds. (Cold Spring Harbor Laboratory Press).

Schad, G.A. (1989). Morphology and life history of Strongyloides stercoralis. In Strongyloidiasis a major roundworm infection of man, D.I. Grove, ed. (London: Taylor and Francis), pp. 85-104.

Shao, H., Li, X., Nolan, T J., Massey, H.C., Jr., Pearce, E J., and Lok, J.B. (2012). Transposon-mediated chromosomal integration of transgenes in the parasitic nematode Strongyloides ratti and establishment of stable transgenic lines. PLoS Pathog. 8, e1002871. Abstract Article

Shoop, W.L., and Corkum, K.C. (1987). Maternal transmission by Alaria marcianae (Trematoda) and the concept of amphiparatenesis. J. Parasitol. 73, 110-115. Abstract Article

Shoop, W.L., Michael, B.F., Eary, C.H., and Haines, H.W. (2002). Transmammary transmission of Strongyloides stercoralis in dogs. J. Parasitol. 88, 536-539. Abstract Article

Speare, R. (1989). Identification of species of Strongyloides. In Strongyloidiasis a major roundworm infection of man, D.I. Grove, ed. (London: Taylor and Francis), pp. 11-84.

Spinner, W.G., Thompson, F.J., Emery, D.C., and Viney, M.E. (2012). Characterisation of genes with a putative key role in the parasitic lifestyle of the nematode Strongyloides ratti. Parasitol. 139, 1317-1328. Abstract Article

Stephenson, L.S., Latham, M.C., and Ottesen, E.A. (2000). Malnutrition and parasitic helminth infections. Parasitology 121, S23-S38. Abstract Article

Stewart, T.B., Stone, W.M., and Marti, O.G. (1976). Strongyloides ransomi: prenatal and transmammary infection of pigs of Soltsequential litters from dams experimentally exposed as weanlings. Am. J. Vet. Res. 37, 541-544. Abstract

Stoltzfus, J.D., Massey, H.C., Jr., Nolan, TJ., Griffith, S.D., and Lok, J.B. (2012a). Strongyloides stercoralis age-1: a potential regulator of infective larval development in a parasitic nematode. PLoS One 7, e38587. Abstract Article

Stoltzfus, J.D., Minot, S., Berriman, M., Nolan, T.J., and Lok, J.B. (2012b) RNASeq analysis of the parasitic nematode Strongyloides stercoralis reveals divergent regulation of canonical dauer pathways. PLoS Neg. Trop. Dis. 6, e1854. Abstract Article

Stone, W., and Smith, F.W. (1973). Infection of mammalian hosts by milk-borne nematode larvae: a review. Exp. Parasitol. 34, 306-312. Abstract Article

Thompson, F.J., Mitreva, M., Barker, G.L.A., Martin, J., Waterston, R.H., McCarter, J.P., and Viney, M.E. (2005). An expressed sequence tag analysis of the life-cycle of the parasitic nematode Strongyloides ratti. Mol. Biochem. Parasitol. 142, 32-46. Abstract Article

Thompson, F.J., Barker, G.L.A., Hughes, L., Wilkes, C.P., Coghill J., and Viney, M.E. (2006). A microarray analysis of gene expression in the free-living stages of the parasitic nematode Strongyloides ratti. BMC Genomics 7, 157-177. Abstract Article

Thompson, F.J., Barker, G.L.A., Hughes, L., and Viney, M.E. (2008). Genes important in the parasitic life of the nematode Strongyloides ratti. Molec. Biochem. Parasitol. 158, 112-119. Abstract Article

Thompson, F.J., Barker, G.L.A., Nolan, T., Gems, D., and Viney, M.E. (2009). Transcript profiles of long- and short-lived adults implicate protein synthesis in evolved differences in ageing in the nematode Strongyloides ratti. Mech. Age. Dev. 130, 167-172. Abstract Article 
Tindall, N.R., and Wilson, P.A.G. (1988). Criteria for a proof of migration routes of immature parasites inside hosts exemplified by studies of Strongyloides ratti in the rat. Parasitology 96, 551-563. Abstract Article

Triantaphyllou, A.C., and Moncol, D.J. (1977). Cytology, reproduction, and sex determination of Strongyloides ransomi and S. papillosus. J. Parasitol. 63, 961-973. Abstract Article

Turner, S.A., Maclean, J.D., Fleckenstein, L., and Greenaway, C. (2005). Parenteral administration of ivermectin in a patient with disseminated strongyloidiasis. Am. J. Trop. Med. Hyg. 73, 911-914. Abstract

Viney, M.E. (1994). A genetic analysis of reproduction in Strongyloides ratti. Parasitology 109, 511-515. Abstract Article

Viney, M.E. (1996). Developmental switching in the parasitic nematode Strongyloides ratti. Proc. Biol. Sci. 263, 201-208. Abstract Article

Viney, M.E., and Ashford, R.W. (1990). The ultrastructure of the peri-vulval region of Strongyloides cebus. J. Helminthol. 64, 23-28. Abstract Article

Viney, M.E., and Cable, J. (2011). Macroparasite life-histories. Curr. Biol. 21, R767-R774. Abstract Article

Viney, M.E., Matthews, B.E., and Walliker, D. (1992). On the biological and biochemical nature of cloned populations of Strongyloides ratti. J. Helminthol. 66, 45-52. Abstract Article

Viney, M.E., Matthews, B.E., and Walliker, D. (1993). Mating in the parasitic nematode Strongyloides ratti: Proof of genetic exchange. Proc. Biol. Sci. 254, 213-219. Abstract Article

Viney, M.E. (2002). Environmental control of nematode life cycles. In The Behavioural Ecology of Parasites, E.E. Lewis, J.F. Campbell, M.V.K. Sukhdeo, eds. (Oxford: CABI Publishing), pp. 111-128

Viney, M.E., Brown, M., Omoding, N.E., Bailey, J.W., Gardner, M.P., Roberts, E., Morgan, D., Elliott, A.M., and Whitworth, J.A.G. (2004). Why does HIV infection not lead to disseminated Strongyloidiasis? J. Infect. Dis. 190, 2175-2180. Abstract Article

Viney, M.E., Thompson, F.J., and Crook. M. (2005). TGF- $\beta$ and the evolution of nematode parasitism. Int. J. Parasitol. 35, 1473-1475. Abstract Article

Viney, M.E., Steer, M.D., and Wilkes, C.P. (2006). The reversibility of constraints on size and fecundity in the parasitic nematode Strongyloides ratti. Parasitology 133, 477-483. Abstract Article

Viney, M.E., and Diaz, A. (2012). Phenotypic plasticity in nematodes : evolutionary and ecological significance. Worm 1, 98-106. Abstract Article

Wang, Z., Zhou, X.E., Motola, D.L., Gao, X., Suino-Powell, K., Conneely, A., Ogata, C., Sharma, K.K., Auchus, R.J., Lok, J. B., Hawdon, J.M., Kliewer, S.A., Xu, H.E., and Mangelsdorf, D.J. (2009). Identification of the nuclear receptor DAF-12 as a therapeutic target in parasitic nematodes. Proc. Natl. Acad. Sci. U. S. A. 106, 9138-9143. Abstract Article

Wilkes, C.P., Thompson, F.J., Gardner, M.P., Paterson, S., and Viney, M.E. (2004). The effect of the host immune response on the parasitic nematode Strongyloides ratti. Parasitology 128, 661-669. Abstract Article

Wilkes, C.P., Bleay, C., Paterson, S., and Viney, M.E. (2007). The immune response during a Strongyloides ratti infection of rats. Parasit. Immunol. 29, 339-346. Abstract Article

Yamada, M., Matsuda, S., Nakazawa M., and Arizono, N. (1991). Species-specific differences in heterogonic development of serially transferred free-living generations of Strongyloides planiceps and Strongyloides stercoralis. J. Parasitol. 77, 592-594. Abstract Article

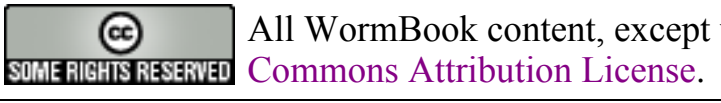

